\title{
Characteristics and risk factors for 28-day mortality of hospital acquired fungemias in ICUs: data from the EUROBACT study
}

José-Artur Paiva ${ }^{1 *}$, José Manuel Pereira ${ }^{1}$, Alexis Tabah ${ }^{2,3,4}$, Adam Mikstacki ${ }^{5}$, Frederico Bruzzi de Carvalho ${ }^{6}$, Despoina Koulenti ${ }^{3,7}$, Stéphane Ruckly ${ }^{4,8}$, Nahit Çakar ${ }^{9}$, Benoit Misset ${ }^{10}$, George Dimopoulos ${ }^{7}$, Massimo Antonelli ${ }^{11}$, Jordi Rello ${ }^{12}$, Xiaochun Ma ${ }^{13}$, Barbara Tamowicz ${ }^{5}$ and Jean-François Timsit $2,4,8,14$

\begin{abstract}
Background: To characterize and identify prognostic factors for 28-day mortality among patients with hospitalacquired fungemia (HAF) in the Intensive Care Unit (ICU).

Methods: A sub-analysis of a prospective, multicenter non-representative cohort study conducted in 162 ICUs in 24 countries.

Results: Of the 1156 patients with hospital-acquired bloodstream infections (HA-BSI) included in the EUROBACT study, 96 patients had a HAF. Median time to its diagnosis was 20 days (IQR 10.5-30.5) and 9 days (IQR 3-15.5) after hospital and ICU admission, respectively. Median time to positivity of blood culture was longer in fungemia than in bacteremia (48.7 h vs. 38.1 h; $p=0.0004$ ). Candida albicans was the most frequent fungus isolated (57.1\%), followed by Candida glabrata (15.3\%) and Candida parapsilosis (10.2\%). No clear source of HAF was detected in $33.3 \%$ of the episodes and it was catheter-related in $21.9 \%$ of them. Compared to patients with bacteremia, HAF patients had a higher rate of septic shock (39.6\% vs. $21.6 \% ; p=0.0003$ ) and renal dysfunction ( $25 \%$ vs. $12.4 \% ; p=0.0023$ ) on admission and a higher rate of renal failure ( $26 \%$ vs. $16.2 \% ; p=0.0273$ ) at diagnosis. Adequate treatment started within $24 \mathrm{~h}$ after blood culture collection was less frequent in HAF patients (22.9\% vs. $55.3 \%$; $p<0.001$ ). The 28-day all cause fatality was $40.6 \%$. According to multivariate analysis, only liver failure (OR 14.35; $95 \% \mathrm{Cl} 1.17-175.6 ; p=0.037$ ), need for mechanical ventilation (OR 8.86; $95 \% \mathrm{Cl}$ 1.2-65.24; $p=0.032$ ) and ICU admission for medical reason (OR 3.87; $95 \% \mathrm{Cl} 1.25-11.99 ; p=0.020$ ) were independent predictors of 28-day mortality in HAF patients.

Conclusions: Fungi are an important cause of hospital-acquired BSI in the ICU. Patients with HAF present more frequently with septic shock and renal dysfunction on ICU admission and have a higher rate of renal failure at diagnosis. HAF are associated with a significant 28 -day mortality rate (40 \%), but delayed adequate antifungal therapy was not an independent risk factor for death. Liver failure, need for mechanical ventilation and ICU admission for medical reason were the only independent predictors of 28-day mortality.
\end{abstract}

\section{Background}

Bloodstream infection(s) (BSI) in the critically ill patients are a major cause of morbidity and mortality. The prevalence varies between centers, representing $15 \%$ of all nosocomial infections in a recent, large, multicenter prevalence study [1]. The prognosis of BSI also varies,

\footnotetext{
* Correspondence: jarturpaiva@gmail.com

'Grupo de Infecção e Sepsis; Emergency and Intensive Care Department, Centro Hospitalar S. João, EPE; Faculty of Medicine, University of Porto, Porto, Portugal

Full list of author information is available at the end of the article
}

depending on several factors related to the host, the pathogen and the antimicrobial agent.

Fungi are responsible for around $20 \%$ of all microbiologically documented infections in the Intensive Care Unit (ICU) [1]. The incidence of invasive fungal infections has increased steadily, namely due to the increasing number of both immunocompromised and critically ill patients. In the last decades, we faced a worldwide rise in the prevalence of candidemia, particularly in the ICU [2-6]. Data from surveillance programs from the 
USA and Europe showed that Candida spp. is responsible for $2-11 \%$ of hospital-acquired BSI (HA-BSI) and it represents $8.3 \%$ of patients with HA-BSI hospitalized in ICUs [7]. It is the fourth cause of nosocomial BSI in the USA and the fifth to the tenth most common pathogen in Europe [8-11].

Candidemia is a severe disease linked to significant morbidity and mortality $[3,12,13]$ ranging from $35-75 \%$ $[14,15]$. Outstandingly, after controlling for confounders, candidemia has been identified as an independent predictor of mortality [16]. In addition, it prolongs hospital length of stay and increases costs associated with patient management $[13,17]$. Therefore, it is important to identify potentially modifiable prognostic factors to improve this poor outcome. Few independent prognostic factors have been identified in critically ill patients with candidemia. Adequate initial therapy is of paramount importance for a successful outcome. In general, early administration of antimicrobial agents is associated with a better outcome [18]. However, contradictory results have been published on the timing of antifungal therapy [19].

The goal of this sub-analysis of the Epidemiology and outcome of hospital-acquired bacteremia (EUROBACT) study was to characterize the population of patients with hospital-acquired fungemia (HAF) admitted to ICUs worldwide and to identify prognostic factors for 28-day mortality, including timing of antifungal therapy, in these patients.

\section{Methods}

A prospective observational multicenter international cohort design was used. The international database was declared to the CNIL (Commission Nationale de l'Informatique et des Libertés). The French ethics committee waived the need for informed consent for French centers. Similar authorization was obtained from countries such as Portugal (Centro Hospitalar S. João), Poland (Poznan University of Medical Sciences) and Australia (Royal Brisbane and Women's Hospital) and it was waived in the other countries due to the observational nature of the study.

\section{Study protocol and definitions}

Patients were enrolled if they had a new diagnosis of HA-BSI and were admitted to an ICU. The study focused on the first episode of HA-BSI, either being ICU-acquired or acquired before admission to ICU. The detailed protocol has been described previously [7]. Data collected for each patient included the dates and times of collection and of positivity of the first positive blood culture; source of infection; presence of sepsis; severity of illness; comorbidities; and infection management, including source control, antimicrobial drugs and adjunctive treatments. Organ dysfunction and organ failure were defined as Sequential Organ Failure Assessment (SOFA) scores $>0$ and $\geq 3$, respectively. All study data were obtained from patient files, and no additional tests were performed for the purpose of the study. Severity of illness was defined at ICU admission using the Simplified Acute Physiology Score (SAPS) II [20] and at HA-BSI diagnosis using the SOFA score [21]. Comorbidities were assessed using the Charlson index and the five markers of the Chronic Health Evaluation from the Acute Physiology and Chronic Health Evaluation (APACHE) II score, as reported by Knaus et al. [22]. Clinical variables and relapses or new episodes of HA-BSI were recorded until ICU discharge, and the all-cause mortality within 28 days of the first positive blood culture were ascertained.

\section{Data management and statistical analysis}

A control quality check has been detailed previously [7]. The statistical analysis was based only on the first episode of HA-BSI, as this was the only episode for which full information was available. The medians and interquartile range (IQR) was computed for continuous data and Fisher's exact test or the chi-square test was performed to compare categorical data. We compared characteristics of patients with bacteremia and patients with fungemia, using univariate hierarchical logistic regression models, including random effects for country and center. Time to death was plotted using Kaplan-Meier curves and compared using a frailty Cox model, treating the center as a random effect.

For patients with fungemia, risk factors for death were analyzed using hierarchical models. The variables were organized into three tiers: country, ICU and patient. To identify factors associated with day- 28 mortality, we built a three-tiered hierarchical logistic mixed model using the GLIMMIX procedure in the SAS software. The influence of country-based and ICU-based variables on the outcome was included through both fixed and random effects. Multilevel modeling takes into account the hierarchical structure of the data, which may manifest as intra-class correlations. To obtain a conservative estimate of the standard error, a separate random-error term should be specified for each level of the analysis. Therefore, to avoid overestimating the significance of risk factors for death by day 28 , we took intra-class correlation into account, and we specified a separate random-error term for each tier. Variables potentially associated with day- 28 mortality ( $p$ values $<0.20$ by univariate analysis) were introduced into the multivariable model and selected using a backward approach. Twoway clinically relevant interactions were tested in the final model. In all analysis, two-sided $p$ values $<0.05$ were deemed statistically significant. No correction for multiple testing was performed. 


\section{Results}

A fungus was recovered from the blood in 96 of the 1,156 patients $(8.3 \%)$ with HA-BSI admitted to an ICU, included in the EUROBACT study [7]. Patients with HAF were mostly male (67.7 \%) with a median age of 61 years (IQR 48-73) and a median SAPS II score of 49 (IQR 41-63) (Table 1). They were mostly admitted to the ICU for medical reasons (63.5\%), $60 \%$ of these with acute respiratory failure requiring ventilator support and $24 \%$ with a cardiac-related syndrome: $35 \%$ of the patients had a Charlson co-morbidity index $\geq 3$. A chronic illness was present in $41.7 \%$ of patients, mainly immunosuppressive (15.6\%), cardiovascular (14.6\%) and respiratory (12.5\%) chronic illnesses.

At ICU admission, at least one organ failure was documented in a significant number of patients (89.6 \%). Respiratory $(82.3 \%)$ and cardiovascular $(63.5 \%)$ were the most prevalent organ dysfunctions followed by neurological (29.2 \%) and renal (25\%). Septic shock was diagnosed in $39.6 \%$ of the patients and it was present at diagnosis of HAF in half of the episodes.

The median time to diagnosis of HAF was 20 days (IQR 10.5-30.5) after hospital admission and 9 days (IQR 3-15.5) after ICU admission (Table 2). In fact, more than half of the episodes (56.3\%) occurred after the first week in the ICU. However, a significant number of patients $(22.9 \%)$ had already presented with HAF on ICU admission.

Median time to blood culture positivity in fungemia was 48.7 hours (IQR 33-81). There was no clear source of fungemia in 32 patients (33.3 \%) and in 21 patients (21.9\%) it was catheter-related, based upon culture results yielding identical microorganisms. The abdomen was the source of infection in 12 patients (12.5\%) (Table 2). Source control was required in $43.8 \%$ of patients and was performed in $39.6 \%$ of the patients (Table 2 ).

The characteristics on admission of patients with fungemia and of those with bacteremia were similar except for a higher rate of septic shock and renal dysfunction in fungemic patients (Table 1). At diagnosis, patients with HAF presented with a significantly higher rate of renal failure than bacteremic patients. Delay from hospital admission to HA-BSI diagnosis was not significantly different between bacteremic and fungemic patients (13 days (7-25) vs 20 days $(10.5-30.5), p=0.13)$. Delay of positivity of culture sampling was significantly longer for fungemia (38.1 hours (21.1-69.2) vs 48.7 (33-81), $p=0.0004$ ) (Table 2 and Fig. 1). There was no significant difference between these two groups of patients in time to death (Fig. 2).

On comparing baseline characteristics in patients with ICU-acquired fungemia $(n=74)$ and $\operatorname{HAF}(n=22)$, the

Table 1 Baseline characteristics of patients with fungemia and patients with bacteremia

\begin{tabular}{|c|c|c|c|}
\hline Variable & Bacteremia patients $(n=1,060)$ & Fungemia patients $(n=96)$ & $P$ value \\
\hline Age, median (IQR) & $62(49-74)$ & $61(48-73.5)$ & 0.7077 \\
\hline Male gender, n (\%) & $691(65.2)$ & $65(67.7)$ & 0.6155 \\
\hline Simplified Acute Physiology Score II, median (IQR) & $48(38-59)$ & $49(41-63)$ & 0.0993 \\
\hline Medical admission, $\mathrm{n}(\%)$ & $611(57.6)$ & $61(63.5)$ & 0.1799 \\
\hline Charlson comorbidity index score, n (\%) & & & 0.3215 \\
\hline 0 & $361(34.1)$ & $25(26)$ & \\
\hline $1-2$ & $367(34.6)$ & $37(38.5)$ & \\
\hline$\geq 3$ & $332(31.3)$ & $34(35.4)$ & \\
\hline At least one chronic illness, n (\%) & $336(31.7)$ & $40(41.7)$ & 0.0629 \\
\hline Immunosuppression, n (\%) & $136(12.8)$ & $15(15.6)$ & 0.5012 \\
\hline Cardiovascular, n (\%) & $103(9.7)$ & $14(14.6)$ & 0.202 \\
\hline Respiratory, n (\%) & $86(8.1)$ & $12(12.5)$ & 0.1286 \\
\hline Renal, n (\%) & $53(5)$ & $8(8.3)$ & 0.1396 \\
\hline Liver, n (\%) & $40(3.8)$ & $4(4.2)$ & 0.9752 \\
\hline At least one organ dysfunction on admission, $\mathrm{n}(\%)$ & $944(89.1)$ & $86(89.6)$ & 0.8491 \\
\hline Cardiovascular, n (\%) & $530(50)$ & $61(63.5)$ & 0.0222 \\
\hline Respiratory, n (\%) & $858(80.9)$ & $79(82.3)$ & 0.7319 \\
\hline Neurologic, n (\%) & $326(30.8)$ & $28(29.2)$ & 0.8062 \\
\hline Renal, n (\%) & $131(12.4)$ & $24(25)$ & 0.0023 \\
\hline Septic shock at admission, n (\%) & $229(21.6)$ & $38(39.6)$ & 0.0003 \\
\hline Mortality at 28 days, n (\%) & $375(35.4)$ & $39(40.6)$ & 0.2307 \\
\hline
\end{tabular}


Table 2 Characteristics of fungemia and bacteremia episodes at diagnosis

\begin{tabular}{|c|c|c|c|}
\hline Variable & Bacteremia patients $(n=1,060)$ & Fungemia patients $(n=96)$ & $P$ value \\
\hline Delay between ICU admission and BSI, days, median (IQR) & $8(3-16)$ & $9(3-15.5)$ & 0.9812 \\
\hline Delay between hospital admission and BSI, days, median (IQR) & $13(7-25)$ & $20(10.5-30.5)$ & 0.1299 \\
\hline Delay to positivity of the blood culture sampling, days, median (IQR) & $38.1(21.1-69.2)$ & $48.7(33-81)$ & 0.0004 \\
\hline Sepsis syndrome & & & 0.5420 \\
\hline Sepsis, n (\%) & $136(12.8)$ & $14(14.6)$ & \\
\hline Severe sepsis, n (\%) & $442(41.7)$ & $34(35.4)$ & \\
\hline Septic shock, n (\%) & $482(45.5)$ & $48(50)$ & \\
\hline SOFA score & & & 0.4812 \\
\hline $0-4, n(\%)$ & $256(24.2)$ & $17(17.7)$ & \\
\hline $5-7, \mathrm{n}(\%)$ & $284(26.8)$ & $24(25)$ & \\
\hline $8-11, \mathrm{n}(\%)$ & $300(28.3)$ & $31(32.3)$ & \\
\hline$\geq 12, \mathrm{n}(\%)$ & $220(20.8)$ & $24(25)$ & \\
\hline SOFA respiratory $\geq 3, n$ (\%) & $499(47.1)$ & $45(46.9)$ & 0.9385 \\
\hline SOFA cardiovascular $\geq 3, \mathrm{n}(\%)$ & $441(41.6)$ & $47(49)$ & 0.2493 \\
\hline SOFA neurological $\geq 3, \mathrm{n}(\%)$ & $340(32.1)$ & $32(33.3)$ & 0.6578 \\
\hline SOFA renal $\geq 3, \mathrm{n}(\%)$ & $172(16.2)$ & $25(26)$ & 0.0273 \\
\hline SOFA coagulation $\geq 3, \mathrm{n}(\%)$ & $134(12.6)$ & $15(15.6)$ & 0.5577 \\
\hline SOFA liver $\geq 3, \mathrm{n}(\%)$ & $81(7.6)$ & $7(7.3)$ & 0.7845 \\
\hline Need for mechanical ventilation, n (\%) & $946(89.2)$ & $84(87.5)$ & 0.6661 \\
\hline Hypotension, n (\%) & $529(49.9)$ & $54(56.3)$ & 0.3263 \\
\hline Presumed source of infection & & & 0.3336 \\
\hline No clear source, n (\%) & $242(22.8)$ & $32(33.3)$ & \\
\hline Catheter-related, n (\%) & $226(21.3)$ & $21(21.9)$ & \\
\hline Respiratory, n (\%) & $230(21.7)$ & $14(14.6)$ & \\
\hline Intra-abdominal, n (\%) & $122(11.5)$ & $12(12.5)$ & \\
\hline Urinary, n (\%) & $43(4.1)$ & $4(4.2)$ & \\
\hline Others, n (\%) & $67(6.3)$ & $6(6.3)$ & \\
\hline Multiple sources, n (\%) & $130(12.3)$ & $7(7.3)$ & \\
\hline Source control & & & 0.9820 \\
\hline Not required, n (\%) & $590(55.7)$ & $54(56.3)$ & \\
\hline Done, n (\%) & $429(40.5)$ & 38 (39.6) & \\
\hline Required not done, n (\%) & $41(3.9)$ & $4(4.2)$ & \\
\hline Delay of adequate treatment & & & $<0.0001$ \\
\hline$<24 \mathrm{~h}$ & $586(55.3)$ & $22(22.9)$ & \\
\hline$>24 \mathrm{~h}$ and $\leq 120 \mathrm{~h}$ & $335(31.6)$ & $59(61.5)$ & \\
\hline$>120 \mathrm{~h}$ & $40(3.8)$ & $9(9.4)$ & \\
\hline Never & $99(9.3)$ & $6(6.2)$ & \\
\hline
\end{tabular}

SOFA Sequential Organ Failure Assessment

only difference was more frequent presence of at least one chronic illness $(p<0.01)$, namely immunosupression $(p<0.01)$ and cardiovascular disease $(p=0,05)$ in patients with HAF (Additional file 1: Table S1). The only significant difference in the characteristics of fungemia episodes at diagnosis, was a higher coagulation SOFA score in patients with HAF $(p<0.01)$ (Additional file 1: Table S2).

Candida albicans was the most frequent fungus isolated (57.1 \%) followed by Candida glabrata (15.3\%) and Candida parapsilosis (10.2\%) (Table 3). Non-albicans Candida accounted for $39.6 \%$ of HAF in this study. 


\section{Delay to positivity of the BC sampling}

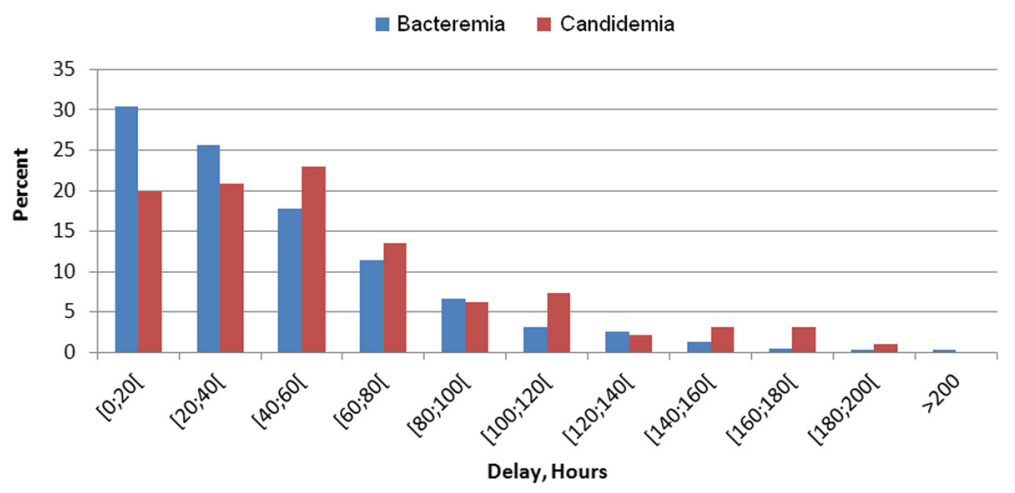

Fig. 1 Delay to positivity of culture sampling. BC - Blood cultures

More than one fungus was recovered from the blood of two of the patients. A mixed (bacterial and fungal) infection was documented in $15.6 \%$ of the patients with fungemia.

In this study, $93.8 \%$ of the patients received adequate treatment: $22.9 \%$ of the patients received adequate treatment in the first 24 hours after blood culture collection, which was a significantly lower percentage than for bacteremia $(55.3 \%, p<0.001)$.

The 28-day all-cause mortality was $40.6 \%(\mathrm{n}=39)$, slightly higher than in bacteremia (35.4\%). Nonsurvivors were older (64 years, IQR $50-76$ vs 57 years IQR 46-71, $p=0.318$ ) and had higher SAPS II score (52 IQR 43-63 vs 47 IQR 37-63, $p=0.095$ ) but the differences were not statistically significant (Table 4$)$. Fungemic patients admitted for a medical reason had significantly higher 28 -day mortality ( $76.9 \%$ vs $54.4 \%, p=$
0.038). Neither the Charlson comorbidity index nor the presence of a chronic illness had a significant impact on the outcome. No association was found between sepsis syndrome severity at HAF diagnosis and mortality. In univariate analysis, the SOFA score at HA-BSI diagnosis was associated with a worse outcome. A SOFA score $\geq 8$ was more frequent in non-survivors (77 \% vs $43.8 \%, p=0.004)$. Furthermore, non-survivors had significantly higher SOFA scores for cardiovascular organ $(p=0.015)$ and respiratory organ $(p=0.0019)$ dysfunction. The presumed source of infection and the pathogen did not affect 28-day mortality. Delay of adequate treatment also did not affect outcome (Table 4). The proportion of patients who received adequate antifungal therapy in the first 24 hours after positive blood culture collection was higher (though not statistically significant) in non-survivors than that in survivors (28.2 \% vs. $19.3 \%$; $p=0.694)$.

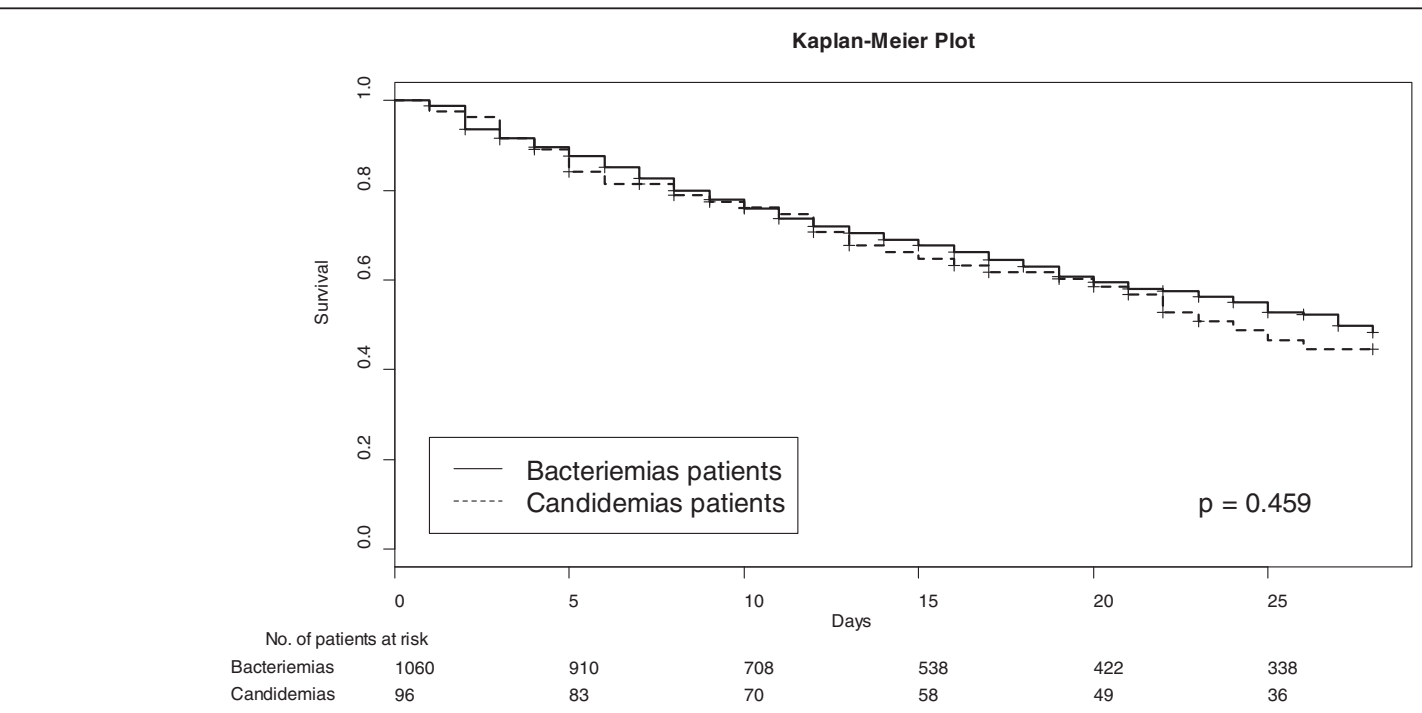

Fig. 2 Time to death for fungemic and bacteremic patients 
Table 3 Distribution of the 98 fungal pathogens

\begin{tabular}{|c|c|c|c|}
\hline \multirow[t]{2}{*}{ Pathogen } & $\begin{array}{l}\text { All } \\
\text { fungemia }\end{array}$ & $\begin{array}{l}\text { ICU acquired } \\
\text { fungemia } \\
\text { patients }\end{array}$ & $\begin{array}{l}\text { Hospital acquired } \\
\text { fungemia } \\
\text { patients }\end{array}$ \\
\hline & $\begin{array}{l}n=98(100 \\
\%)\end{array}$ & $\begin{array}{l}n=75(76.5 \\
\%)\end{array}$ & $n=23(23.5 \%)$ \\
\hline Candida albicans, n (\%) & $56(57,1)$ & $44(58.7)$ & $12(52.7)$ \\
\hline Candida glabrata, n (\%) & $15(15,3)$ & $12(16.0)$ & $3(13.0)$ \\
\hline $\begin{array}{l}\text { Candida parapsilosis, n } \\
(\%)\end{array}$ & $10(10,2)$ & $7(9.3)$ & $3(13.0)$ \\
\hline Other Candida, n (\%) & $7(7.1)$ & $5(6.7)$ & $2(8.7)$ \\
\hline Candida tropicalis, n (\%) & $6(6.1)$ & $4(5.3)$ & $2(8.7)$ \\
\hline Other fungi, n (\%) & $3(3.1)$ & $2(2.7)$ & $1(4.4)$ \\
\hline Candida krusei, n (\%) & $1(1.0)$ & $1(1.3)$ & 0 \\
\hline
\end{tabular}

On multivariable analysis (Table 5), the only variables independently associated with 28-day mortality were: liver SOFA score $\geq 3$ (odds ratio (OR) 14.35, $95 \%$ CI 1.17175.6, $p=0.037$ ), need for mechanical ventilation (OR 8.86, $95 \%$ CI 1.2-65.24, $p=0.032$ ) and ICU admission for medical reasons (OR 3.87, $95 \%$ CI 1.25-11.99, $p=0.020$ ). On multivariate analysis SOFA score was the only risk factor for death at 28 days in the subpopulation of patients with ICU-acquired fungemia $(p=0,0085)$.

\section{Discussion}

This prospective, multicenter, observational study discloses that fungemia accounted for $8.3 \%$ of the hospital-acquired BSI in patients admitted to the ICU. The mortality rate in HAF was high (40\%), but delayed adequate antifungal therapy was not an independent risk factor for death. The presence of septic shock and renal dysfunction on ICU admission and renal failure at BSI diagnosis were the only factors associated with fungemia in patients with BSI. In patients with HAF, multivariate logistic regression analysis identified liver SOFA score $\geq 3$, need for mechanical ventilation and ICU admission for medical reasons as independent predictors of 28-day mortality.

Candidemia in critically ill patients is considered to be a severe and life-threatening condition. Recent data show that ICU and hospital mortality rates are usually between $36 \%$ and $61 \%[5,6,14,15,18,23-26]$. In our study, we observed 28 day-mortality of $40.6 \%$ which is in agreement with former findings [27] and is lower than the rates observed in recent Australian [19], Brazilian [26] and Spanish-Italian [18] studies.

Characteristics of bacteremic and fungemic patients at admission are remarkably similar, namely in terms of the comorbidity index, immunosuppression and chronic organ illnesses, and only the presence of septic shock and renal dysfunction on ICU admission and renal failure at diagnosis were more frequent in patients with HA-BSI and fungemia than in those with bacteremia. Although delay in appropriate treatment was significantly longer for HAF, the outcome was similar in patients with fungemia and those with bacteremia.

Kumar et al. [28] observed strong correlation between shorter time to onset of antimicrobial treatment and reduced mortality in patients with septic shock. They showed that over the first 6 hours after the onset of persistent or recurrent hypotension, each hour of delay in initiating effective antimicrobial therapy was associated with a mean reduction in survival of $7.6 \%$, including the subgroup of patients with fungal infection. Nevertheless, the results of studies addressing the potential benefit of early antifungal therapy in patients with candidemia are conflicting.

In a small prospective multicenter study $(\mathrm{n}=46 \mathrm{pa}$ tients) [14], there was a higher (though not significant, $p=0.06$ ) probability of survival among patients receiving early antifungal therapy (within $\leq 48$ hours) compared with those treated 48 hours or more after the diagnosis of candidemia. A few years later, an independent association between delayed antifungal therapy ( $>48$ hours) and in-hospital mortality (hazard ratio (HR) 2.1, $95 \% \mathrm{CI}$ 1.0-4.4, $p=0.05)$ was reported by Blot et al. [27]. According to Morrell et al. [29], mortality doubles when antifungal agents are administered $\geq 12$ hours after the collection of the first positive blood culture and in another retrospective analysis of 230 patients with candidemia [30], initiation of fluconazole $\leq 24$ hours after the first positive blood culture was associated with a significantly lower mortality rate. This positive effect of early antifungal therapy on survival was further confirmed in a group of patients with candidemia-associated septic shock who received treatment within 15 hours of blood culture collection [31]. Finally, in 216 patients hospitalized in five teaching hospitals in Italy and Spain (18), who had septic shock attributable to candidemia, adequate antifungal therapy, meaning both infecting organism susceptibility and adequate antifungal dosage within the first 24 hours of culture positivity, was one of the factors associated with 30-day survival.

However, some recent studies did not observe this beneficial association between timing of antifungal therapy and mortality in patients with candidemia [32-34]. Kludze-Forson et al. [35] observed a higher in-hospital mortality rate in patients receiving antifungal therapy within the first 24 hours (50\%) compared to 24-48 hours $(28 \%)$ and more than 48 hours $(32 \%)$ after blood culture collection. More recently, in a large retrospective study that included 446 patients with candidemia [36], there was neither a significant association between time from positive culture to administration of appropriate antifungal therapy and 30-day mortality, nor between timing of appropriate antifungal therapy and microbiological resolution of Candida bloodstream infection. 
Table 4 Risk factors for death at 28 days in the subpopulation with candidemia (univariate analysis)

\begin{tabular}{|c|c|c|c|}
\hline Variable & Dead $(n=39$ patients) & Alive ( $n=57$ patients) & $P$ value \\
\hline Age, median (IQR) & $64(50-76)$ & $57(46-71)$ & 0.318 \\
\hline SAPS II, median (IQR) & $52(43-63)$ & $47(37-63)$ & 0.095 \\
\hline Male, n (\%) & $28(71.8)$ & $37(64.9)$ & 0.448 \\
\hline Medical admission, n (\%) & $30(76.9)$ & $31(54.4)$ & 0.038 \\
\hline Charlson comorbidity index score, n (\%) & & & 0.5816 \\
\hline 0 & $8(20.5)$ & $17(29.8)$ & \\
\hline $1-2$ & $17(43.6)$ & $20(35.1)$ & \\
\hline$\geq 3$ & $14(35.9)$ & $20(35.1)$ & \\
\hline At least one chronic illness, n (\%) & $16(41)$ & $24(42.1)$ & 0.982 \\
\hline Immunosuppression, n (\%) & $8(20.5)$ & $7(12.3)$ & 0.271 \\
\hline Cardiovascular, n (\%) & $3(7.7)$ & $11(19.3)$ & 0.1245 \\
\hline Respiratory, n (\%) & $5(12.8)$ & $7(12.3)$ & 0.811 \\
\hline Renal, n (\%) & $2(5.1)$ & $6(10.5)$ & 0.431 \\
\hline Liver, n (\%) & $3(7.7)$ & $1(1.8)$ & 0.174 \\
\hline At least one organ dysfunction on admission, n (\%) & $37(94.9)$ & $49(86)$ & 0.187 \\
\hline Cardiovascular, n (\%) & $25(64.1)$ & $36(63.2)$ & 0.901 \\
\hline Respiratory, n (\%) & $34(87.2)$ & $45(78.9)$ & 0.284 \\
\hline Neurologic, n (\%) & $13(33.3)$ & $15(26.3)$ & 0.375 \\
\hline Renal, n (\%) & $9(23.1)$ & $15(26.3)$ & 0.752 \\
\hline Delay between ICU admission and fungemia, days, median (IQR) & $8(4-13)$ & $10(3-21)$ & 0.229 \\
\hline Delay between hospital admission and fungemia, days, median (IQR) & $20(10-29)$ & $21(11-32)$ & 0.591 \\
\hline Sepsis syndrome, n (\%) & & & 0.301 \\
\hline Sepsis & $3(7.7)$ & $11(19.3)$ & \\
\hline Severe sepsis & $14(35.9)$ & $20(35.1)$ & \\
\hline Septic shock & $22(56.4)$ & $26(45.6)$ & \\
\hline SOFA, n (\%) & & & 0.004 \\
\hline $0-4$ & $3(7.7)$ & $14(24.6)$ & \\
\hline $5-7$ & $6(15.4)$ & $18(31.6)$ & \\
\hline $8-11$ & $12(30.8)$ & 19 (33.3) & \\
\hline$\geq 12$ & $18(46.2)$ & $6(10.5)$ & \\
\hline SOFA score, respiratory, n (\%) & & & 0.019 \\
\hline 0 & $4(10.3)$ & $8(14)$ & \\
\hline 1 & $1(2.6)$ & $7(12.3)$ & \\
\hline 2 & $8(20.5)$ & $23(40.4)$ & \\
\hline 3 & $13(33.3)$ & $16(28.1)$ & \\
\hline 4 & $13(33.3)$ & $3(5.3)$ & \\
\hline SOFA score, cardiovascular, n (\%) & & & 0.015 \\
\hline 0 & $9(23.1)$ & 19 (33.3) & \\
\hline 1 & $4(10.3)$ & $12(21.1)$ & \\
\hline 2 & $1(2.6)$ & $4(7)$ & \\
\hline 3 & $4(10.3)$ & $13(22.8)$ & \\
\hline 4 & $21(53.8)$ & $9(15.8)$ & \\
\hline
\end{tabular}


Table 4 Risk factors for death at 28 days in the subpopulation with candidemia (univariate analysis) (Continued)

\begin{tabular}{|c|c|c|c|}
\hline SOFA score, neurological, n (\%) & & & 0.249 \\
\hline 0 & $13(33.3)$ & $17(29.8)$ & \\
\hline 1 & $5(12.8)$ & $14(24.6)$ & \\
\hline 2 & $7(17.9)$ & $8(14)$ & \\
\hline 3 & $4(10.3)$ & $11(19.3)$ & \\
\hline 4 & $10(25.6)$ & $7(12.3)$ & \\
\hline SOFA score, renal, n (\%) & & & 0.122 \\
\hline 0 & $11(28.2)$ & $32(56.1)$ & \\
\hline 1 & $8(20.5)$ & $10(17.5)$ & \\
\hline 2 & $5(12.8)$ & $5(8.8)$ & \\
\hline 3 & $5(12.8)$ & $3(5.3)$ & \\
\hline 4 & $10(25.6)$ & $7(12.3)$ & \\
\hline SOFA score, coagulation, n (\%) & & & 0.125 \\
\hline 0 & $19(48.7)$ & $42(73.7)$ & \\
\hline 1 & $6(15.4)$ & $3(5.3)$ & \\
\hline 2 & $4(10.3)$ & $7(12.3)$ & \\
\hline 3 & $6(15.4)$ & $4(7)$ & \\
\hline 4 & $4(10.3)$ & $1(1.8)$ & \\
\hline SOFA score, liver, n (\%) & & & 0.142 \\
\hline 0 & $26(66.7)$ & $46(80.7)$ & \\
\hline 1 & $6(15.4)$ & $6(10.5)$ & \\
\hline 2 & $1(2.6)$ & $4(7)$ & \\
\hline 3 & $6(15.4)$ & $1(1.8)$ & \\
\hline Need for mechanical ventilation, n (\%) & $37(94.9)$ & $47(82.5)$ & 0.094 \\
\hline Hypotension, n (\%) & $25(64.1)$ & $29(50.9)$ & 0.208 \\
\hline Presumed source of infection, $\mathrm{n}(\%)$ & & & 0.573 \\
\hline No clear source & $12(30.8)$ & $20(35.1)$ & \\
\hline Catheter-related & $6(15.4)$ & $15(26.3)$ & \\
\hline Intra-abdominal & $8(20.5)$ & $4(7)$ & \\
\hline Respiratory & $6(15.4)$ & $8(14)$ & \\
\hline Urinary & $2(5.1)$ & $2(3.5)$ & \\
\hline Others & $2(5.1)$ & $4(7)$ & \\
\hline Multiple sources, n (\%) & $3(7.7)$ & $4(7)$ & \\
\hline Delay of adequate treatment, $\mathrm{n}(\%)$ & & & 0.694 \\
\hline$<24 \mathrm{~h}$ & $11(28.2)$ & $11(19.3)$ & \\
\hline$>24 \mathrm{~h}$ and $\leq 48 \mathrm{~h}$ & $9(23.1)$ & $14(24.6)$ & \\
\hline$>48 \mathrm{~h}$ and $\leq 120 \mathrm{~h}$ & $12(30.8)$ & $24(42.1)$ & \\
\hline$>120 \mathrm{~h}$ or never & $7(17.9)$ & $8(14)$ & \\
\hline Antifungal treatment on the day of blood culture sampling, $\mathrm{n}(\%)$ & $8(20.5)$ & $8(14)$ & 0.491 \\
\hline Candida pathogen, n (\%) & & & 0.693 \\
\hline Candida albicans & $23(59)$ & $33(57.9)$ & \\
\hline Candida parapsilosis & $5(12.8)$ & $5(8.8)$ & \\
\hline Other fungus & $11(28.2)$ & $19(33.3)$ & \\
\hline
\end{tabular}


Table 5 Risk factors for death at 28 days for candidemia subpopulation (multivariate analysis)

\begin{tabular}{|c|c|c|c|}
\hline Variable & $\begin{array}{l}\text { Estimate } \\
\text { (standard error) }\end{array}$ & $\begin{array}{l}\text { Odds ratio } \\
(95 \% \mathrm{Cl})\end{array}$ & $P$ value \\
\hline \multicolumn{4}{|l|}{ Delay of adequate treatment } \\
\hline$\leq 24$ h, n (\%) & Reference & 1 & 0.8069 \\
\hline$>24 \mathrm{~h}$ and $\leq 48 \mathrm{~h}, \mathrm{n}(\%)$ & $-0.24(0.74)$ & $0.79(0.18 ; 3.41)$ & 0.7466 \\
\hline$>48 \mathrm{~h}$ and $\leq 120 \mathrm{~h}, \mathrm{n}(\%)$ & $-0.61(0.66)$ & $0.54(0.15 ; 2.0)]$ & 0.3570 \\
\hline$>120$ h or never, $\mathrm{n}(\%)$ & $-0.15(0.90)$ & $0.86(0.15 ; 5.14)$ & 0.8717 \\
\hline Medical admission & $1.35(0.57)$ & $3.87(1.25 ; 11.99)$ & 0.0197 \\
\hline SOFA score, liver ( $\geq 3$ ) & $2.66(1.26)$ & $14.35(1.17 ; 175.6)$ & 0.0373 \\
\hline $\begin{array}{l}\text { Need for mechanical } \\
\text { ventilation }\end{array}$ & $2.18(1.00)$ & $8.86(1.2 ; 65.24)$ & 0.0325 \\
\hline
\end{tabular}

Variables entered into the selection were the Simplified Acute Physiology Score II at ICU admission (per point); medical admission; septic shock at admission; type of ICU (open/closed); Sequential Organ Failure Assessment (SOFA) score, coagulation ( $\geq 3)$; SOFA score, liver $(\geq 3)$; SOFA score, neurological $(\geq 3)$; SOFA score, renal $(\geq 3)$; mechanical ventilation and delay of adequate treatment

Studies addressing only ICU-acquired candidemia, also failed to show this positive impact $[19,25,37]$. In the study of Marriott et al. [19], mean time to initiation of antifungal therapy was similar for non-survivors and survivors ( $2.0 \pm 1.3$ days vs $2.3 \pm 1.6$ days, $p=0.13$ ), and Charles et al. [37] also observed that early therapy ( $\leq 48$ hours after onset of candidemia) did not improve the outcome of patients with candidemia. Finally, a prospective, Spanish multicenter study showed that inadequate antifungal therapy was a factor independently associated with early mortality (0-7 days) in candidemia, but it had no impact on late mortality (8-30 days) [38].

In our study, four factors may contribute to the absence of impact of delayed adequate antifungal therapy on mortality. First, in critically ill patients, antifungal therapy is more likely to be started earlier than in nonICU patients and, in fact, $22.9 \%$ of the patients received adequate treatment within the first 24 hours and almost half of them within the first 48 hours after blood culture collection. Second, among critically ill patients any relationship between mortality and initiation of antifungal therapy may be hidden by the power of the patient's acute illness as a determinant of outcome. Third, only half of our fungemia patients had septic shock at BSI diagnosis and the impact of early therapy is understandably higher in this subgroup of patients. Finally, timing to source control is a possible confounder that could not be analyzed, namely we did not collect data on the presence of a catheter, except on removal if it was deemed the source of the bloodstream infection.

Few prognostic factors have been identified in ICU patients with candidemia. In this cohort, the only independent prognostic factors associated with 28-day mortality were liver SOFA score $\geq 3$, need for mechanical ventilation and ICU admission for medical reasons. Acute severity of illness is one important prognostic factor in candidemia. Among candidemic patients, the severity of organ dysfunction at fungemia onset evaluated by the SOFA score is a risk factor for mortality [39]. In our study, only liver failure was independently associated with 28-day mortality. In Candida bloodstream infection, this association between liver disease and outcome was previously reported but only for patients with chronic liver illness, which has a significant $\mathrm{HR}$ as an independent risk factor for 30-day mortality (HR 2.15, $95 \%$ CI 1.48-3.13, $p<0.001$ ) [34]. There is also a relationship between other scores, such as the APACHE II score, and mortality in candidemic patients $[14,23-25,40]$. In our study, we used the SAPS II score but despite being higher in non-survivors ( 52 vs 47 , $p=0.095$ ), we could not prove it was an independent risk factor for mortality. A possible explanation is the fact that this score was calculated on admission and may not reflect the severity of the patients at the time of BSI diagnosis.

The need for mechanical ventilation as an independent risk factor for mortality has also been reported by several authors. In a prospective, multicenter, observational French study [5], the use of mechanical ventilation increased the odds of dying in the ICU 2.54 times (95\% CI 1.33-4.82, $p=0.0045)$. A similar result was reported in another large retrospective study $(\mathrm{n}=987$ patients with candidemia) [41] that showed an independent association between mechanical ventilation and 30-day mortality (OR 2.61, $95 \%$ CI 1.81-3.78, $p<0.001$ ). An even higher impact was observed in a study with 173 ICUacquired episodes of candidemia, in which the need of mechanical ventilation was associated with a four times increased risk of death (95\% CI 1.93-8.41, $p<0.001)$ [19]. Almirante et al. also reported that intubation (OR 7.5, $95 \%$ CI 2.6-21.1) was associated with higher odds of 30day mortality in a cohort of 345 patients with candidemia, of whom $33 \%$ were in the ICU at diagnosis [42].

In our cohort, medical patients had a lower probability of survival. Interestingly, the same result was reported by Charles et al. [37] a few years ago in a small study of 51 ICU patients with candidemia, in which medical patients had a higher mortality rate compared to surgical patients ( $85 \%$ vs $45.2 \%$ ) and prior surgery was an independent factor associated with survival (HR 0.25, $95 \%$ CI 0.09-0.67, $p<0.05)$. Other authors [19] observed that the chances of dying with candidemia are 6.97 times higher in patients without multi-trauma (95 \% CI 1.64-29.67, $p=0.009$ ).

Although our study is multicenter, prospective and includes a significant number of patients, it has some limitations. It is not representative of the populations of healthcare systems in the 24 participating countries, and in some countries the number of patients included was very small. Each participating ICU performed investigations and laboratory testing according to their local protocols. The data were entered into the electronic case report 
form by investigators at each center, which may have increased the risk of inconsistency. Finally, some important variables with potential impact on the outcome were not considered, namely the antifungal agent used, its appropriateness and the timing of central venous catheter removal.

\section{Conclusion}

In summary, this multicenter international study showed that fungi are an important cause of HA-BSI in patients admitted to the ICU. No significant differences were observed between patients with bacteremia and fungemia, except for the presence of septic shock and renal dysfunction on ICU admission and renal failure at diagnosis, which were more frequent in HAF. Fungemia is significantly associated with 28-day all-cause mortality. We were not able to detect an independent association between timing of antifungal therapy and outcome, and only liver failure, need for mechanical ventilation and ICU admission for medical reasons were independent risk factors associated with mortality.

\section{Key messages}

- A fungus is likely to be the cause of a hospitalacquired BSI in patients with septic shock and renal dysfunction on ICU admission or with renal failure at BSI diagnosis

- In patients with hospital-acquired fungemia, the presence of liver failure, the need for mechanical ventilation and ICU admission for medical reasons significantly increase the odds of dying at day 28

\section{Additional file}

Additional file 1: Table S1. Baseline characteristics of patients with fungemia. Table $\mathbf{S 2}$ Characteristics of fungemia episodes at diagnosis. (DOCX $19 \mathrm{~kb})$

\section{Abbreviations \\ APACHE: Acute Physiology and Chronic Health Evaluation; BSI: bloodstream infection(s); HA-BSI: hospital-acquired bloodstream infection(s); HAF: hospital- acquired fungemia; HR: hazard ratio; ICU: Intensive Care Unit; IQR: interquartile range; OR: odds ratio; SAPS: Simplified Acute Physiology Score; SOFA: Sepsis-related Organ Failure Assessment.}

\section{Competing interests}

JAP has received a speaker or advisory board honorarium from Astellas, Gilead, Merck-Sharp-Dohme, Novartis and Pfizer. JMP has received a speaker honorarium from Gilead, Merck-Sharp-Dohme and Pfizer. GD has received a speaker and advisory board honorarium from Bayer, Pfizer, Astellas and Cubist and research grants from EC "Magic Bullet". MA has received research grants from Orion, Merck-Sharp-Dohme, Covidien and Pfizer and board participations and an honorarium from Basilea, Pfizer, Cubist, Intersurgical and Maquet. JR has received a speaker or advisory board honorarium and research grants from Pfizer and Astellas. JFT has received a speaker or advisory board honorarium from Astellas, Bayer, Abbott, Gilead, Merck-SharpDohme, Novartis, 3M and Pfizer and research grants from Astellas, Merck-SharpDohme, 3M and Pfizer. AT, FBC and DK have no conflicts of interest.

\section{Authors' contributions}

JAP and JMP conducted the primary analysis and drafted the manuscript. AT contributed to the study design, data collection and analysis. JFT participated in the study conception and design, collection of data and analysis. JR and GD contributed to the study design and data collection. All authors have made substantial contribution to the revising and final approval of the version to be published.

\section{Acknowledgements}

The EUROBACT study was designed by the infection section of the ESICM. The study was endorsed by the European Critical Care Research Network (ECCRN) in May 2009 and received the Clinical Research Award with a research grant of $€ 20,000$ from the ECCRN in November 2011.

The manuscript was written on behalf of the EUROBACT study group listed below. Grants were obtained from Université Grenoble 1 and European Society of Intensive Care Medicine.

Members of the EUROBACT study group Steering Committee: Alexis Tabah, Despoina Koulenti, Stijn Blot, Jean-Ralph Zahar, Maité Garrouste-Orgeas, and Jean-François Timsit.

EUROBACT Scientific Committee: Jean Carlet, Christian Brun-Buisson, Georges Dimopoulos, Claude Martin, and Jordi Rello.

Statistics and methodology: Jean Francois Timsit, Alexis Tabah, and Kevin Laupland.

Biostatistician: Aurélien Vesin.

Study monitoring: Alexis Tabah and Sylvain Anselme.

Country coordinators: Australia: Jeffrey Lipman; Austria: Andreas Valentin; Belgium: Johan Decruyenaere; Brazil: Frederico Bruzzi de Carvalho; Canada: Kevin Laupland; China: Xiaochun Ma; Croatia: Ivan Gornik; France: Benoit Misset; Germany: Wolfgang A. Krueger; Greece: Despoina Koulenti; Hungary: Akos Csomos; Italy: Massimo Antonelli; Japan: Toshiki Mizobe; Morocco: Said Motaouakkil; The Netherlands: Marc J.M. Bonten; Poland: Adam Mikstacki; Portugal: José-Artur Paiva; Republic of Serbia: Uros Batranovic; Romania: Daniela Filipescu; Spain: Jordi Valles \& Ricard Ferrer; Switzerland: Philippe Eggimann; Tunisia: Fekri Abroug; Turkey: Nahit Çakar; United Arab Emirates: Hussain Al Rahma.

ICU investigators, listed by ICU (by country):

Jeffrey Lipman (Prof., MD) - Department of Intensive Care Medicine, Royal Brisbane \& Women's Hospital, Brisbane, Australia; Anne Leditschke (MD) and Helen Rodgers (RN) - Canberra Hospital Intensive Care Unit, Canberra Hospital, Canberra, Australia; David Milliss (ASC Prof.) and Thomas Gottlieb (ASC Prof.) - Intensive Care Services, Concord Hospital, NSW, Australia; Stuart Baker (MD) and Brigit Roberts (RN) - ICU, Sir Charles Gairdner Hospital, Perth, Australia; Peter Kraffft (MD) and Silvia Bernreiter (MD) - Intensiv 1b, Hospital Rudolfstiftung, Vienna, Austria; Pieter Depuydt (MD) - Intensieve Zorg, Universitair Ziekenhuis Gent, Ghent, Belgium; Philippe Jamaer (MD) - Icu A3 And C3, Jessa Hospital, Campus Virga Jesse, Hasselt, Belgium; Hervé Lebbinck (MD) Iz, Az Sint Augustinus Veurne, Veurne, Belgium; Frederico Bruzzi De Carvalho (MD) and Juliana Pereira (MD) - Centro De Terapia Intensiva, Hospital Mater Dei, Belo Horizonte, Brazil; Aline Camille Yehia (MD), Felipe Carrhá Machado (MD), and Ana Luiza Horta de Sa Carneiro (MD) - Cti Hospital Julia Kubitschek, Julia Kubitschek, Belo Horizonte, Brazil; Antonio Fagundes Jr. (MD) - Unidade de Terapia Intensiva, Hospital do Coração do Brasil, Brasília - DF, Brazil; Fernando Rodriguez (MD) - Cti Geral, Hospital de Clínicas Niterói, Niterói, Brazil; Marcio Soares (MD, PhD) and Jorge Salluh (MD, PhD) - Cti, Instituto Nacional de Cancer, Rio De Janeiro, Brazil; Renata Beranger (MD) - ICU, São Lucas Hospital, Rio de Janeiro, Brazil; Marcelo Lugarinho (MD) - Cti Do Hospital De Clínicas Mario Lioni, Hospital De Clínicas Mario Lioni, Rio de Janeiro, Brazil; Alexandre Carvalho (MD) and Livia, Reis (RN) - Uti 1-2-3, Udi Hospital, São Luis Ma, Brazil; Cyntia de Lima (MD) - Uti Clínica, Hospital Santa Izabel, Salvador, Brazil; Claudio Piras (Prof., MD, PhHD) - CPC, Vitoria Apart Hospital, Vitoria, Brazil; Eliana Caser (Prof.) and Jansen Falcão (MD) - Uti Geral Adulto, Centro Integrado De Atenção A Saúde - Cias Unimed Vitória, Vitória - ES, Brazil; Kevin B Laupland (MD) - ICU, Peter Lougheed Centre, Calgary, Canada; Kevin B. Laupland (MD) ICU, Foothills Medical Centre, Calgary, Canada; Kevin B. Laupland (MD) - CVICU, Foothills Medical Centre, Calgary, Canada; Kevin B. Laupland (MD) - ICU, Rockyview General Hospital, Calgary, Canada; Zhidan Zhang (MD) and Xiaochun Ma (MD) - Department Of Critical Care Medicine, The First Affiliated Hospital Of China Medical University, Shenyang, China; Xian Yao Wan (Prof.) - Jiu Zhi Zhang (Prof.) - Department Of Intensive Care Medicine, The First Affiliated Hospital Of Dalian Medical University, Dalian, China; Ke-Jian Qian (Prof.) - Liang Xia (MD) - Intensive Care Unit, The First Affiliated Hospital Of Nan Chang 
University, Nan Chang, China; Congshan Yang (MD) - Department Of Critical Care Medicine, Zhongda Hospital, Southeast University, Nanjing, China; Deng Lijing (MD) - Central ICU, West China Hospital Of Sichuan University, Chengdu, China; Meili Duan (MD) - Department Of Critical Care Medicine, Beijing Friendship Hospital, Capital Medical University, Beijing, China; Tang Zhanhong (Prof.) and Pan Yiping (MD) - Intensive Care Unit, The First Hospital Of Guangxi Medical University, Nanning, China; Wang Yongqiang (MD) - Luo Ning (MD) ICU, Tianjin First Center Hospital, Tianjin, China; Zhou Li-Xin (Prof.) and Li JinQuan (MD) - Intensive Care Unit, The Affiliated Foshan Hospital Of Sun Yat-Sen University, Foshan, China; Xian Yao Wan (Prof.) - ICU, Beijing Tongren Hospital, Beijing, China; Ivan Gornik (MD) - Medical Intensive Care Unit, University Hospiral Centre Zagreb, Zagreb, Croatia; Vesna Degoricija (Prof., MD, PhD) - Medical ICU, University Hospital Sisters Of Mercy And University Of Zagreb School Of Medicine, Zagreb, Croatia; Achille Kouatchet (MD) - Département De Réanimation Médicale Et Médecine Hy, Chu Angers, Angers Cedex 9, France; Gaetan Plantefeve (MD) and Olivier Pajot (MD) - Réanimation Polyvalente, Ch Victor Dupouy, Argenteuil, France; Hatem Kallel (MD) - Polyvalent ICU, Andrée Rosemon, Cayenne, France; Lherm Thierry (MD) and Kalfon Pierre (MD) Réanimation Polyvalente, Louis Pasteur, Chartres, France; David Petitpas (MD) - Réanimation polyvalente, Chg Châlons En Champagne, Châlons En Champagne, France; Henry Lessire (MD) - Réanimation Médicale, Ch Pasteur, Colmar, France; Christian Brun-Buisson (Prof., MD) - Tai Pham (MD) - Réanimation Médicale, Chu Henri Mondor, Créteil, France; Djillali Annane (Prof.) and Virginie Maxime (MD) - Réanimation Médicale, Chu, Garches, France; Herault Marie-Christine (MD) - Reanimation Polyvalente Chirurgicale, Chu Michallon, Grenoble, France; Sybille Merceron (MD) Medico-Surgical ICU, André Mignot Versailles Hospital Centre, Le Chesnay, France; Eric Kipnis (ASC Prof., MD, PhD) and Marielle Boyer-Besseyre (ASC Prof., MD) - Réanimation Chirurgicale, CHRU De Lille, Lille, France; Benoit Tavernier (Prof., MD, PhD) and Sebastien Faivre (MD) - Réanimation Neurochirurgicale, CHRU de Lille, Lille, France; Voillet Francois (MD) and Renaud Lepaul Ercole (MD) - Medical Intensive Care Unit, Hopital North, Marseille, France; Vincent Willems (MD) - Réanimation Polyvalente, Centre Hospitalier De Meaux, Meaux, France; Kada Klouche (MD, PhD) and Jean Philippe Delabre (MD) Medical Intensive Care Unit, Lapeyronie University Hospital, Montpellier, France; Cartier Julien (MD) and Gleyse Brigitte (RN) - Service De Réanimation Polyvalente, Ch De Montélimar, Montélimar, France; Sebastien Gibot (MD, PhD) - Réanimation Médicale, Hopital Central, Nancy, France; Bruno Mégarbane (Prof., MD, PhD) - Réanimation Médicale Et Toxicologique, Hôpital Lariboisière, Paris, France; Philippe Seguin (MD, PhD) - Réanimation Chirurgicale, Chu De Rennes, Rennes, France; Anne Launoy (MD) - Service De Réanimation Chirurgicale Hautepierre, Hôpitaux Universitaires De Strasbourg, Strasbourg, France; Tixier Vincent (MD) - Medical, Gabriel Montpied, Clermont-Ferrand, France; Samir Jamali (MD) - Usi (Unité De Soins Intensifs), Centre Hospitalier De Dourdan, Dourdan, France; Silvia Calvino (RN) and Alexis Tabah (MD) - Réanimation Médicale, Grenoble Teaching Hospital, Grenoble, France; Michel Durand (MD) and Marine Rossi-Blancher (MD) - Reanimation Cardiovasculaire et Thoracique, Hopital Michallon, Grenoble, France; Alexandre Debrumetz (MD) and Elie Azoulay (Prof.) - Service De Réanimation Médicale, CHU Saint Louis, Paris, France. Julien Charpentier (MD) and Jean-Daniel Chiche (Prof., MD, PhD) - Réanimation Médicale Polyvalente, Cochin, Paris, France; Maité Garrouste-Orgeas (MD) and Benoit Misset (MD) - Réanimation Polyvalente, Gh Paris Saint-Joseph, Paris, France; Gernot Marx (Prof., MD) - Klinik Für Operative Intensivmedizin Und Intermediate Care, University Hospital Aachen, Aachen, Germany; Wolfgang A. Krueger (MD, PhD) - Anaesthesiology and Intensive Care Medicine, Clinics Of Constance, Constance, Germany; Thomas Felbinger (MD, PhD) - Department of Anaesthesiology, The Munich Municipal Hospitals Ltd., Munich, Germany; Alexandra Heininger (MD, PhD) ICU 20-22, Universitätsklinik Für Anaesthesiologie Und Intensivmedizin, Tuebingen, Germany; Ingo Voigt (MD) - Kardiologische Intensivstation, Elisabeth Krankenhaus Essen, Essen, Germany; Torsten Schroeder (MD) Interdisziplinäre Intensivstation, Karl-Olga Krankenhaus, Stuttgart, Germany; Ioannis Pneumatikos (Prof., MD, PhD) - Vassiliki Theodorou (MD) - Critical Care Department, University Hospital of Alexandroupoli, Alexandroupoli, Greece; Despoina Koulenti (MD) - Apostolos Armaganidis (Prof., MD, PhD) - 2nd Critical Care Department, Attikon University Hospital, Athens, Greece; Pavlos Myrianthefs (ASC Prof., MD, PhD) - Alexandra Gavala (MD) - Athens University,
School Of Nursing, ICU, "Kat" General Hospital, Athens, Greece; Chara Nikolaou (MD) - Katerina Kounougeri (MD) - Department of Critical Care Medicine, Konstantopouleion General Hospital of Nea Ionia, Athens, Greece; Christina Routsi (ASC Prof., MD, PhD) - Adamantia Liapikou (MD) - University ICU Department, Evangelismos General Hospital, Athens, Greece; Christodoulos Nathanail (MD, PhD) - Pirros Tsakas (MD) - Intensive Care Unit, General Hospital of Arta, Arta, Greece; Andreas Karabinis (MD, PhD) - Christos Tsakalakis (MD) Critical Care Department, General Hospital "G. Genimatas", Athens, Greece; Kostas Mandragos (MD,PhD) - Chrysostomos Katsenos (MD) - Intensive Care Unit, Red Cross (Erythros Stavros) Hospital, Athens, Greece; Georgios Anthopoulos (MD) - Georgios Choutas (MD) - Intensive Care Unit, 251 Air Force General Hospital, Athens, Greece; Anastasia Koutsikou (MD) - Ilona Nikolaidou (MD) - Intensive Care Unit (Surgical), General Hospital of Athens "Asklepieion Voulas", Athens, Greece; Vasileios Bekos (MD) - Anna Spring (RN) - Intensive Care Unit, Naval Hospital of Athens, Athens, Greece; Haralambos Paskalis (MD) - Vassiliki Psallida (MD) - Intensive Care Unit, Hygeia General Hospital, Athens, Greece. Aikaterini loakeimidou (MD) - Alexandra Lahana (MD, PhD) - Intensive Care Unit, Athens Veterans Hospital (Nimits), Athens, Greece; Paraskevi Plantza (MD) - Aikaterini Nodarou (MD) - Icu Kaa Sotiria General Hospital, Sotiria General Hospital, Athens, Greece; Antonia Koutsoukou (ASC Prof., MD, PhD) - Magdalini Kyriakopoulou (MD) - ICU 1st Resp. Medicine Depart. Athens University, Sotiria General Hospital, Athens, Greece; Martha Michalia (MD) - Phyllis Clouva-Molyvdas (MD) - Department of Critical Care Medicine, "Thriassion" General Hospital of Eleusis, Elefsina, Athens, Greece; Dimitrios Sfyras (MD) - Christos Georgiadis (MD) - Intensive Care Unit, General Hospital of Lamia, Lamia, Greece; Pavlos Polakis (MD) - Spiros Papanikolaou (MD) - Intensive Care Unit, "Peiraiko Therapeftirio, Pireus, Greece; Christos Christopoulos (MD, PhD) - Efstratia Vrettou (MD) - Intensive Care Unit, General Hospital of Pyrgos, Pyrgos, Greece; Kostoula Arvaniti (MD, $\mathrm{PhD}$ ) - Dimitrios Matamis (MD, PhD) - Critical Care Department, "Papageorgiou" General Hospital of Thessaloniki, Thessaloniki, Greece; Theoniki Paraforou (MD, PhD) - Kyriaki Spiropoulou (MD) - ICU, General Hospital Of Trikala, Trikala, Greece; Dimitris Georgopoulos (Prof., MD, PhD) - Maria Klimathianaki (MD) - Critical Care Department, University General Hospital of Heraklion, Crete, Heraklion, Greece; Georgios Nakos (Prof., MD, PhD) - Vasilios Koulouras (ASC Prof.F, MD, PhD) - Critical Care Department, University Hospital of Ioannina, Ioannina, Greece; Apostolos Komnos (MD, PhD) - Achilleas Chovas (MD, PhD) Department Of Critical Care Medicine, General Hospital of Larisa, Larisa, Greece; Athanasios Prekates (MD, PhD) - Eleni Magira (MD, PhD) - Critical Care Department, "Tzaneion" General Hospital of Pireus, Pireus, Greece; Maria Giannakoy (MD, PhD) - Eleni Gkeka (MD) - Intensive Care Unit, "Ahepa" General Hospital, Thessaloniki, Greece; Eleni Antoniadou (MD, PhD) - Elli Antypa (MD,PhD) - Critical Care Department, General Hospital Of Thessaloniki "G. Genimatas", Thessaloniki, Greece; Nikoletta GritsiGerogianni (MD,PhD) - Christina Kydona (MD) - Critical Care Department, "Hippokrateion" General Hospital of Thessaloniki, Thessaloniki, Greece; Epaminondas Zakynthinos (ASC Prof., MD, PhD) - Nikolas Tzovaras (MD) Critical Care Department, University Hospital of Larissa, Larissa, Greece; Akos Csomos (MD, PhD) - Surgical Intensive Care, Semmelweis University, Budapest, Hungary; Csóka Gábor (MD) - Sürgősségi Beteg Ellátó Egység, Fővárosi Önkormányzat Szent Imre Kórház, Budapest, Hungary; Borbala Mikos (MD) - György Velkey (MD) - Pediatric Anaesthesia And Intensive Care Unit, Bethesda Children's Hospital of The Hungarian Reformed Church, Budapest, Hungary; Eszter Vitális (MD) - Auguszta Sebészet Intenzív, The Medical And Health Science Centre of the University of Debrecen, Debrecen, Hungary; Nóra, Ágota Kovács (MD) - Aito Flór Ferenc, Kistarcsa, Hungary; Lajos Bogar (Prof., MD, PHD) - Tamas Kiss (MD) - Department of Anaesthesia and Intensive Therapy, University Of Pécs 400 Bed Clinic, Pécs, Hungary; Zollei Eva (MD) - Medical ICU, University of Szeged, Szeged, Hungary; Valerio Mangani (MD) - Giorgio Tulli (Prof) - Intensive Care Unit, S.Giovanni Di Dio, Firenze, Italy. Guido Stefania (MD) - Ronco Chiara (student) - Centro Rianimazione, Maggiore Della Carità, Novara, Italy; Massimo Antonelli (Prof.) - Luca Montini (MD) Rianimazione E Terapia Intensiva, Policlinico Universitario A. Gemelli, Rome, Italy; Monica Rocco (Prof., MD) - Giorgia Citterio (MD) - Centro Di Rianimazione, Policlinico Umberto I, Rome, Italy; Shigeki Fujitani (MD) - Emergency \& Critical Care Medicine, St. Marianna University School of Medicine Hospital, Kanagawa, Japan; Koji Hosokawa (MD) - Intensive Care Unit, Kyoto Prefectural University Of Medicine, Kyoto, Japan; Motaouakkil Said (Prof.) - Charra Boubaker 
(Prof.) - Reanimation Medicale, CHU Ibn Rochd, Casablanca, Morocco; Marcus Schultz (Prof., MD, PhD, FCCP) - Annelou Van Der Veen (RN) - ICU, Academic Medical Center, Amsterdam, Netherlands; Heleen Aardema (MD) - Intensive and Respiratory Care Unit, University Medical Center Groningen, Groningen, Netherlands; Dennis Bergmans (MD, PhD) - Rik Schoemakers (BSC) - Department Of Intensive Care, Maastricht University Medical Centre, Maastricht, Netherlands; Ronald Wesselink (MD, PhD) - ICU, St. Antonius Ziekenhuis, Nieuwegein, Netherlands; Evelien A.N. Oostdijk (MD) - Marc J.M., Bonten (Prof., MD, PhD) Department of Medical Microbiology, University Medical Center Utrecht, Utrecht, Netherlands; Iwona Dragan (MD) - ICU, General Hospital, Gniezno, Poland; Włodzimierz Kostyrka (MD) - Micu, Szpital Powiatowy, Ostrów Wielkopolski, Poland; Barbara Tamowicz (MD, PhD) - Adam Mikstacki (MD, PhD) - Department of Anaesthesiology and Intensive Therapy, Poznan University of Medical Sciences, Regional Hospital, Poznan, Poland; Piotr Smuszkiewicz (MD, PhD) - Department of Anaesthesiology \& Intensive Therapy, University Hospital, Poznan, Poland; Jacek Nadolski (MD, PhD) Oa I It, Wielkopolska Center of Pulmonology and Thoracic surgery, Poznań, Poland; Robert Choma (MD) - Oddział Anestezjologii I Intensywnej Terapii, Szpital W Śremie, Śrem, Poland; Wladyslaw Koscielniak (MD) - Pawel Pietraszek (MD) - Oddzial Anestezjologii I Intesywnej Terapii, Regional Hospital Zielona Gora, Zielona Gora, Poland; Edward Maul (MD) - Serviço De Medicina Intensiva, Hospital Central Do Funchal, Funchal, Portugal. Anabela Bártolo (MD) - Salomé Martins - Ucip, Chaa - Guimarães, Guimarães, Portugal; Isabel Miranda (MD) Mariana Oliveira - Ucip02, Hospital De St. António Dos Capuchos, Centro Hospitalar De Lisboa Central, E.P.E., Lisboa, Portugal; Carlos França (Prof.) - Ana Tornada (MD) - SMI, Hospital De Santa Maria, Lisbon, Portugal; Luís Telo (MD) - Leonardo Ferreira (MD) - Ucip, Pulido Valente, Lisboa, Portugal; Teresa Cardoso (MD) - Unidade De Cuidados Intensivos Polivalente, Hospital De Santo António, Porto, Portugal; Lurdes Santos (PhD) - Alcina Ferreira (MD) - Uci-Di, Hospital S. João, Porto, Portugal; José Manuel Pereira (MD) - Ucip Geral, Hospital S João, Porto, Portugal; Celeste Dias (MD) - UCI Neurocriticos, Hospital Sao Joao, Porto, Portugal; Maria Conceição Dias (MD) - UCIPU - Ucip Urgencia, Hospital De S. João, Porto, Portugal; Ana J. Marques (MD) Paula Castelões (MD) - Ucipolivalente Do Chvngaia, Hospital Santos Silva Centro Hospitalar Vila Nova De Gaia, Vila Nova Gaia, Portugal; Uros Batranovic (MD) - Srdjan Gavrilovic (MD) - Intensive Care Unit, Institute For Pulmonary Diseases of Vojvodina, Sremska Kamenica, Republic of Serbia; Daniela Filipescu (Prof., MD, PhD) - Cardiac Anesthesia And Intensive Care, Emergency Institute Of Cardiovascular Diseases, Bucharest, Romania; Francisco Alvarez-Lerma (PhD) Maria Pilar Gracia (PhD) - Intensive Care Unit, Hospital Del Mar, Barcelona, Spain; Fernando Armestar-Rodriguez (MD) - Eduard, Mesalles-Sanjuán (MD) - Medicina Intensiva, Hospital Universitari Germans Trias I Pujol, Badalona, Spain; Nerea Lopez De Arbina (MD) - Josep Sirvent (MD) - Servicio De Medicina Intensiva, Hospital Universitari De Girona Dr Josep Trueta, Girona, Spain; Pau Garro (MD) Uci General, Hospital General De Granollers, Granollers (Barcelona), Spain; Juan Ramón Cortés Cañones (MD) - Unidad Cuidados Intensivos, Complexo Hospitalario Ourense Cristal Piñor, Orense, Spain; Armando Blanco (MD, PhD) Lara Marqués (MD, PhD) - Unidad De Medicna Intensiva I, Hospital Universitario Central De Asturias (Huca), Oviedo, Spain; Josu Insausti (MD) - Iñigo Martija (MD) - Uci, Hospital De Navarra, Pamplona, Spain; Jordi Valles (MD, PhD) Ricard Ferrer (MD, PhD) - Critical Care Center, Hospital Sabadell, Sabadell, Spain; Alejandro Ubeda (MD) - Francisco Lucena (MD) - Polyvalent ICU, H.U Valme, Seville, Spain; Maricarmen Gilavert Cuevas (MD) - Uci, Hospital Universitario Joan Xxiii-Instituto Pere Virgili, Tarragona, Spain; Rafael Zaragoza (MD) - Susana Sancho (MD) - ICU, Hospital Univ. Dr. Peset, Hospital Universitario Dr. Peset, Valencia, Spain; Markus Laube (MD) - Madeleine Rothen (MD) Intensivstation, Spitalzentrum, Biel, Switzerland; Philippe Eggimann (MD) Jean-Luc Pagani (MD) - Service De Médecine Intensive Adulte, Chuv, Lausanne, Switzerland; Samia Ayed (MD) - Service De Reanimation Medicale, CHU Tahar Sfar, Mahdia, Tunisia; Islem Ouanes (MD) - Fekri Abroug (Prof.) - Réanimation Polyvalente, Chu Fattouma Bourguiba, Monastir, Tunisia; Dilek Özcengiz (Prof.) - Reanimation, Cukurova Medical University, Adana, Turkey; Seyhan Yağar (MD, PhD) - Cardiovascular Surgery, ICU, Türkiye Yüksek Ihtisas Hospital, Ankara, Turkey; Süheyla Ünver (MD, ASC Prof.) Yeliz Irem Tunçel (MD) - Anestesia Intensive Care Unit, Ankara Dr Abdurrahman Yurtaslan Onkoloji E. A. Hastanesi, Ankara, Turkey; Unase Buyukkocak (Prof., MD) - Esra Aykac (Resident) - Intensive Care Unit and Anaesthesia, Kirikkale University, The School of Medicine Hospital, Kirikkale, Turkey; Ahmet COŞAR (Prof., MD) Hüseyin Oğuz Yilmaz (MD) - Anesteziyoloji Ve Reanimasyon Ad Ybü, Gülhane Askeri Tıp Akademisi, Ankara, Turkey; Arash Pirat (ASC Prof.) - Pinar Zeyneloglu
(ASC Prof.) - Surgical Intensive Care Unit, Baskent University Hospital, Ankara, Turkey; Nermin Kelebek Girgin (MD) - Halis Akalın (Prof., MD) - Anaesthesiology and ICU, Uludag University Medical Faculty, Bursa, Turkey; Hulya Sungurtekin (MD, Prof) - Simay Serin (Prof., MD) - Anaesthesiology and ICU, Pamukkale University, Denizli, Turkey; I. Ozkan Akinci (ASC Prof.) - Neuro Icu, Istanbul Medical Faculty, Istanbul, Turkey; Tayfun Adanir (MD) - Atilla Sencan (MD) Anaesthesiology and ICU, Ataturk Training And Research Hospital, Izmir, Turkey; Ahmet Dilek (ASC Prof., MD) - Mikail Yüksel Intensive Care Unit, Ondokuz Mayis University, School of Medicine, Samsun, Turkey; Ismail KATI (ASC Prof.) - Ugur Goktas (ASC Prof.) - Anaesthesia and Intensive Care Unit, Yuzuncu Yil University Medical Faculty, Van, Turkey; Ashraf El Houfi (MD, MS, FRCP) - Micu-Sicu, Dubai Hospital, Dubai, United Arab Emirates.

\section{Author details}

Grupo de Infecção e Sepsis; Emergency and Intensive Care Department, Centro Hospitalar S. João, EPE; Faculty of Medicine, University of Porto, Porto, Portugal. ${ }^{2}$ Université Grenoble 1, U 823, Albert Bonniot Institute; Team 11: Outcome of mechanically ventilated patients and respiratory cancers, Grenoble, France. ${ }^{3}$ Burns, Trauma, and Critical Care Research Center, The University of Queensland, Butterfield Street, Brisbane, Australia. ${ }^{4}$ Outcomerea Organization, Paris, France. ${ }^{5}$ Department of Anaesthesiology and Intensive Therapy, Regional Hospital in Poznan, Poznan University of Medical Sciences, Poznan, Poland. ${ }^{6}$ Infectious and Tropical Diseases Intensive Care Unit, Hospital Eduardo de Menezes, Fundação Hospitalar do Estado de Minas Gerais, Belo Horizonte, MG, Brazil. 'DDepartment of Critical Care, University Hospital ATTIKON, Medical School University of Athens, Athens, Greece. ${ }^{8}$ Decision Sciences in Infectious Disease (DesclD) Prevention, Control and Care, UMR 1137 Paris Diderot University, Sorbonne, Paris, France. ${ }^{9}$ Department of Anaesthesiology and Intensive Care, Istanbul University and Istanbul Medical School, Istanbul, Turkey. ${ }^{10}$ Université Paris Descartes, Paris Sorbonne Cité, Medical-surgical ICU, Groupe hospitalier Paris Saint-Joseph, Paris, France. ${ }^{11}$ Department of Intensive Care and Anaesthesiology, Policlinico Universitario A. Gemelli-Università Cattolica del Sacro Cuore, Rome, Italy. ${ }^{12}$ Critical Care Department, Hospital Vall d'Hebron, Universitat Autònoma de Barcelona, Barcelona, Spain. ${ }^{13}$ Department of Critical Care Medicine, The First Affiliated Hospital Of China Medical University, Shenyang, China. ${ }^{14}$ Medical and Infectious Diseases Intensive Care Unit, Bichat University Hospital, Paris Diderot University, Paris 75018, France.

Received: 12 November 2015 Accepted: 10 February 2016 Published online: 09 March 2016

\section{References}

1. Vincent JL, Rello J, Marshall J, Silva E, Anzueto A, Martin CD, et al. International study of the prevalence and outcomes of infection in intensive care units. JAMA. 2009;302:2323-9.

2. Beck-Sague C, Jarvis WR. Secular trends in the epidemiology of nosocomial fungal infections in the United States, 1980-1990. J Infect Dis. 1993;167:1247-51.

3. Wisplinghoff $H$, Bischoff $T$, Tallent SM, Seifert $H$, Wenzel RP, Edmond MB. Nosocomial bloodstream infections in US hospitals: analysis of 24,179 cases from a retrospective nationwide surveillance study. Clin Infect Dis. 2004;39: 309-17.

4. Bassetti M, Right E, Costa A, Fasce R, Molinari MP, Rosso R, et al. Epidemiological trends in nosocomial candidemia in intensive care. BMC Infectious Dis. 2006;6:21.

5. Leroy O, Gangneux JP, Montravers P, Mira JP, Gouin F, Sollet JP, et al. Epidemiology, management, and risk factors for death of invasive Candida infections in critical care: a multicenter, prospective, observational study in France (2005-2006). Crit Care Med. 2009;37:1612-8.

6. Kett DH, Azoulay E, Echeverria PM, Vincent JL, Extended Prevalence of Infection in ICU Study (EPIC II) Group of Investigators. Candida bloodstream infections in intensive care units: analysis of the extended prevalence of infection in intensive care unit study. Crit Care Med. 2011;39:665-70.

7. Tabah A, Koulenti D, Laupland K, Misset B, Valles J, Bruzzi de Carvalho F, et al. Characteristics and determinants of outcome of hospital-acquired bloodstream infections in intensive care units: the EUROBACT International Cohort Study. Intensive Care Med. 2012;38:1930-45.

8. Arnold HM, Micek ST, Shorr AF, Zilberberg MD, Labelle AJ, Kothari S, et al. Hospital resource utilization and costs of inappropriate treatment of candidemia. Pharmacotherapy. 2010;30:361-8. 
9. Bassetti M, Trecarichi EM, Righi E, Sanguinetti M, Bisio F, Posteraro B, et al. Incidence, risk factors, and predictors of outcome of candidemia: survey in 2 Italian university hospitals. Diagn Microbiol Infect Dis. 2007;58:325-31.

10. Bouza $E$, Munoz P. Epidemiology of candidemia in intensive care units. Int J Antimicrob Agents. 2008;32:S87-91.

11. Picazo JJ, Gonzalez-Romo F, Candel FJ. Candidemia in the critically ill patient. Int J Antimicrob Agents. 2008;32:S83-5.

12. Falagas ME, Apostolou KE, Papas VD. Attributable mortality of candidemia: A systematic review of matched cohort and case control studies. Eur J Clin Microbiol Infect Dis. 2006;25:419-25.

13. Gudlaugsson O, Gillespie S, Lee K. Attributable mortality of nosocomial candidemia, revisited. Clin Infect Dis. 2003;37:1172-7.

14. Nolla-Salas J, Sitges-Serra A, Leon-Gil C, Martinez-Gonzalez J, Leon-Regidor MA, Ibanez-Lucia P, et al. Candidemia in nonneutropenic critically ill patients: analysis of prognostic factors and assessment of systemic antifungal therapy. Study Group of Fungal Infection in the ICU. Intensive Care Med. 1997:23:23-30.

15. Voss A, le Noble JL, Verduyn Lunel FM, Foudraine NA, Meis JF. Candidemia in intensive care unit patients: risk factors for mortality. Infection. 1997;25:8-11.

16. Lundberg JS, Perl TM, Wiblin T, Costigan MD, Dawson J, Nettleman MD, et al. Septic shock: an analysis of outcomes for patients with onset on hospital wards versus intensive care units. Crit Care Med. 1998;26:1020-4.

17. Wey SB, Mori M, Pfaller MA, Woolson RF, Wenzel RP. Hospital-acquired candidemia. The attributable mortality and excess length of stay. Arch Intern Med. 1988;148:2642-5.

18. Bassetti M, Righi E, Ansaldi F, Merelli M, Cecilia T, De Pascale G, et al. A multicenter study of septic shock due to candidemia: outcomes and predictors of mortality. Intensive Care Med. 2014;40:839-45.

19. Marriot D, Playford EG, Chen S, Slavin M, Nguyen Q, Ellis D, et al. Determinants of mortality in non-neutropenic ICU patients with candidaemia. Critical Care. 2009;13:R115.

20. Le Gall JR, Lemeshow S, Saulnier F. A new simplified acute physiology score (SAPS II) based on a European/North American multicenter study. JAMA 1993:270:2957-63.

21. Vincent JL, Moreno R, Takala J, Willatts S, De Mendonça A, Bruining H, et al. The SOFA (Sepsis-related Organ Failure Assessment) score to describe organ dysfunction/failure. On behalf of the Working Group on Sepsis-Related Problems of the European Society of Intensive Care Medicine. Intensive Care Med. 1996;22:707-10.

22. Knaus WA, Draper EA, Wagner DP, Zimmerman JE. APACHE II: a severity of disease classification system. Crit Care Med. 1985;13:818-29.

23. Labelle AJ, Micek ST, Roubinian N, Kollef MH. Treatment-related risk factors for hospital mortality in Candida bloodstream infections. Crit Care Med. 2008;36:2967-72

24. Holley A, Dulhunty J, Blot S, Lipman J, Lobo S, Dancer C, et al. Temporal trends, risk factors and outcomes in albicans e non-albicans candidaemia: an international epidemiological study in four multidisciplinary intensive care units. Int J Antimicrob Agents. 2009;33:554. e1-554.e7.

25. González de Molina FJ, León C, Ruiz-Santana S, Saavedra P, the CAVA Study Group. Assessment of candidemia-attributable mortality in critically ill patients using propensity score matching analysis. Crit Care. 2012;16:R105.

26. Colombo AL, Guimarães T, Sukienik T, Pasqualotto AC, Andreotti R, QueirozTelles $F$, et al. Prognostic factors and historical trends in the epidemiology of candidemia in critically ill patients: an analysis of five multicenter studies sequentially conducted over a 9-year period. Intensive Care Med. 2014;40:1489-98.

27. Blot S, Vandewoude KH, Hoste EA, Colardyn FA. Effects of Nosocomial Candidemia on Outcomes of Critically III Patients. Am J Med. 2002;113:480-5.

28. Kumar A, Roberts D, Wood KE, Light B, Parrillo JE, Sharma S, et al. Duration of hypotension before initiation of effective antimicrobial therapy is the critical determinant of survival in human septic shock. Crit Care Med. 2006;34:1589-96.

29. Morrell M, Fraser VJ, Kollef MH. Delaying the empiric treatment of candida bloodstream infection until positive blood culture results are obtained: a potential risk factor for hospital mortality. Antimicrob Agents Chemother. 2005:49:3640-5

30. Garey KW, Rege M, Pai MP, Mingo DE, Suda KJ, Turpin RS, et al. Time to initiation of fluconazole therapy impacts mortality in patients with candidemia: a multi-institutional study. Clin Infect Dis. 2006;43:25-31.
31. Patel GP, Simon D, Scheetz M, Crank CW, Lodise T, Patel N. The effect of time to antifungal therapy on mortality in Candidemia associated septic shock. Am J Ther. 2009;16:508-11.

32. Parkins MD, Sabuda DM, Elsayed S, Laupland KB. Adequacy of empirical antifungal therapy and effect on outcome among patients with invasive Candida species infections. J Antimicrob Chemother. 2007;60:613-8.

33. Klevay MJ, Ernst EJ, Hollanbaugh JL, Miller JG, Pfaller MA, Diekema DJ. Therapy and outcome of Candida glabrata versus Candida albicans bloodstream infection. Diagn Microbiol Infect Dis. 2008;60:273-7.

34. Arendrup MC, Sulim S, Holm A, Nielsen L, Nielsen SD, Knudsen JD, et al. Diagnostic issues, clinical characteristics and outcomes for patients with fungemia. J Clin Microbiol. 2011;49:3300-8.

35. Kludze-Forson M, Eschenauer GA, Kubin CJ, Della-Latta P, Lam SW. The impact of delaying the initiation of appropriate antifungal treatment for Candida bloodstream infection. Med Mycol. 2010;48:436-9.

36. Grim SA, Berger K, Teng C, Gupta S, Layden JE, Janda WM, et al. Timing of susceptibility-based antifungal drug administration in patients with Candida bloodstream infection: correlation with outcomes. J Antimicrob Chemother. 2012;67:707-14.

37. Charles PE, Doise JM, Quenot JP, Aube H, Dalle F, Chavanet P, et al. Candidemia in critically ill patients: difference of outcome between medical and surgical patients. Intensive Care Med. 2003;29:2162-9.

38. Puig-Asensio M, Padilla B, Garnacho-Montero J, Zaragoza O, Aguado JM Zaragoza $\mathrm{R}$, et al. Epidemiology and predictive factors for early and late mortality in Candida bloodstream infections: a population-based surveillance in Spain. Clin Microbiol Infect. 2015:21:491-500.

39. Pratikaki M, Platsouka E, Sotiropoulou C, Douka E, Paramythiotou E, Kaltsas $P$, et al. Epidemiology, risk factors for and outcome of candidaemia among non-neutropenic patients in a Greek intensive care unit. Mycoses. 2011;54:154-61.

40. Garnacho-Montero J, Díaz-Martín A, García-Cabrera E, Ruiz Pérez de Pipaón M, Hernández-Caballero C, Lepe-Jiménez JÁ. Impact on hospital mortality of catheter removal and adequate antifungal therapy in Candida spp. bloodstream infections. J Antimicrob Chemother. 2013;68:206-13.

41. Guimarães T, Nucci M, Mendonça JS, Martinez R, Brito LR, Silva N, et al. Epidemiology and predictors of a poor outcome in elderly patients with candidemia. Intern J Infect Dis. 2012;16:e442-7.

42. Almirante B, Rodriguez D, Park BJ, Cuenca-Estrella M, Planes AM, Almela M, et al. Epidemiology and predictors of mortality in cases of Candida Bloodstream infection: results from population-based surveillance, Barcelona, Spain, from 2002 to 2003. J Clin Microbiol. 2005:43:1829-35.

\section{Submit your next manuscript to BioMed Central and we will help you at every step:}

- We accept pre-submission inquiries

- Our selector tool helps you to find the most relevant journal

- We provide round the clock customer support

- Convenient online submission

- Thorough peer review

- Inclusion in PubMed and all major indexing services

- Maximum visibility for your research

Submit your manuscript at www.biomedcentral.com/submit 